October 3, 2016

\title{
VISCOSITY, DENSITY, AND THERMAL CONDUCTIVITY OF ALUMINUM OXIDE AND ZINC OXIDE NANOLUBRICANTS
}

\author{
M. A. KEDZIERSKI ${ }^{1}$, R. BRIGNOLI \\ National Institute of Standards and Technology \\ 100 Bureau Drive, Stop 861, Gaithersburg, MD 20899-8631 USA \\ K. T. QUINE, J. S. BROWN \\ Department of Mechanical Engineering \\ The Catholic University of America \\ 620 Michigan Ave, NE, Washington, DC 20064 USA
}

\begin{abstract}
This paper presents liquid kinematic viscosity, density, and thermal conductivity measurements of eleven different synthetic polyolester-based nanoparticle nanolubricants (dispersions) at atmospheric pressure over the temperature range $288 \mathrm{~K}$ to $318 \mathrm{~K}$. Aluminum oxide $\left(\mathrm{Al}_{2} \mathrm{O}_{3}\right)$ and zinc oxide $(\mathrm{ZnO})$ nanoparticles with nominal diameters of $127 \mathrm{~nm}$ and $135 \mathrm{~nm}$, respectively, were investigated. A good dispersion of the spherical and non-spherical nanoparticles in the lubricant was maintained with a surfactant. Viscosity, density, and thermal conductivity measurements were made for the neat lubricant along with eleven nanolubricants with differing nanoparticle and surfactant mass fractions. Existing models were used to predict kinematic viscosity $( \pm 20 \%)$, thermal conductivity $( \pm 1 \%)$, and specific volume $( \pm 6 \%)$ of the nanolubricant as a function of temperature, nanoparticle mass fraction, surfactant mass fraction, and nanoparticle diameter. The liquid viscosity, density and thermal conductivity were shown to increase with respect to increasing nanoparticle mass fraction.
\end{abstract}

Keywords: colloidal suspension; density; lubricant; thermal conductivity; viscosity; water chiller

\footnotetext{
${ }^{1}$ Corresponding author. Tel./fax: (301) 975-5282/(301) 975-8973. E-mail address: Mark.Kedzierski@ NIST.gov
} 
October 3, 2016

\section{NOMENCLATURE}

\section{$\underline{\text { English Symbols }}$}

$\mathrm{A}_{\mathrm{n}} \quad$ constants in Table $2 \mathrm{n}=0,1,2,3$

$\mathrm{B}_{\mathrm{n}} \quad$ constants in Table $1 \mathrm{n}=0,1$

$D_{\mathrm{p}} \quad$ nanoparticle diameter [m]

$k \quad$ liquid thermal conductivity $\left[\mathrm{W} \cdot \mathrm{m}^{-2} \cdot \mathrm{K}^{-1}\right]$

$T$ absolute fluid temperature [K]

$T_{\mathrm{r}} \quad T / 273.15 \mathrm{~K}[-]$

$U_{\rho} \quad$ expanded uncertainty of density $\left[\mathrm{kg} \cdot \mathrm{m}^{-3}\right]$

$U_{v} \quad$ expanded uncertainty of viscosity $\left[\mathrm{mm}^{2} \cdot \mathrm{s}^{-1}\right]$

$x \quad$ mass fraction [-]

\section{$\underline{\text { Greek symbols }}$}

$\rho \quad$ liquid density $\left[\mathrm{kg} \cdot \mathrm{m}^{-3}\right]$

$v \quad$ liquid kinematic viscosity $\left[\mathrm{mm}^{2} \cdot \mathrm{s}^{-1}\right]$

$v_{o} \quad$ unity viscosity $=1\left[\mathrm{~mm}^{2} \cdot \mathrm{s}^{-1}\right]$

$\phi \quad$ volume fraction of the nanoparticles in the nanolubricant [-]

$\Psi \quad$ sphericity [-]

\section{$\underline{\text { Subscripts }}$}

L pure lubricant

m mixture, measured

$\mathrm{nL}$ nanolubricant

np nanoparticle

p predicted 
October 3, 2016

s surfactant 
October 3, 2016

\section{INTRODUCTION}

Nanolubricants were originally developed to reduce engine wear via the "ball bearing" effect (Tao et al., 1996). Protecting moving surfaces against friction and wear serves a wide range of applications. One proposed application of nanolubricants is to improve the efficiency of compressors in refrigerators (Bi et al., 2007). Compressors have specific requirements for lubricant viscosity. For this reason, knowledge of the viscosity of a nanolubricant is an essential starting point for its application to equipment.

In addition to compressor research, a number of studies have investigated nanolubricants as a way of improving evaporator heat transfer efficiency in HVAC\&R equipment. For example, Henderson et al. (2010) have shown that copper-oxide nanoparticles can improve the flow boiling heat transfer of refrigerant/lubricant mixtures at low vapor qualities by as much as $76 \%$ and that the lubricant can act as a necessary dispersant. Bi et al. (2007) showed that the use of titanium dioxide-based nanolubricants produced energy savings of more than $25 \%$ in domestic refrigerators. Kedzierski and Gong (2009) have shown that copper-oxide nanoparticles can improve refrigerant/lubricant pool boiling by as much as $245 \%$ and Kedzierski $(2011,2012)$ have shown that aluminum-oxide nanoparticles can yield similar enhancements for refrigerant/lubricant pool boiling.

In one model (Kedzierski, 2001), the prediction of the boiling heat transfer performance of refrigerant/lubricant mixtures relies on knowledge of the liquid viscosity, the liquid thermal conductivity, and the liquid density of the neat lubricant. The properties of the lubricant are important for prediction because the lubricant exists in its nearly neat state as an excess layer on the boiling surface (Kedzierski, 2008). For the same reason, the neat properties of a nanolubricant are used to predict the boiling of refrigerant/nanolubricant mixtures (Kedzierski, 2011, 2012). An 
October 3, 2016

additional application for neat nanolubricant properties is that they can be used with mixing rules to predict properties of refrigerant/nanolubricant mixtures. Consequently, the liquid viscosity, density, and thermal conductivity measurements of nanolubricants are not only of interest to tribologist but also of interest to those involved in fundamental research and new designs for improving the efficiency of air-conditioning and refrigeration equipment.

The nanoparticle material, its size and the amount of surfactant used as a dispersant all affect the viscosity, density and thermal conductivity of a nanolubricant. Kedzierski (2013) has shown that the surfactant can either increase or decrease the viscosity of a nanolubricant. Pramod and Teja (2011) have shown that the thermal conductivity of a nanofluid increases with increasing nanoparticle size. Eastman et al. (2001) have shown that highly conductive nanoparticle materials can lead to highly conductive nanofluids. Buongiorno et al. (2009) have shown that both particle geometry and conduction resistance at the nanoparticle-fluid interface influence conductivity, but other proposed effects such as Brownian microconvection, super-conductive liquid layering, and aggregation percolation are not likely to be important. Similarly, Venerus et al. (2010) have demonstrated that viscosity measurements for nanofluids with non-spherical particle shapes can be influenced by shear to a greater degree than nanofluids with spherical particles. Consequently, because nanoparticle characteristics have been identified as of primary importance in determining nanolubricant transport properties, the focus of the present study is to investigate the influence of nanoparticle properties and mass fraction on viscosity, density, and thermal conductivity of selected aluminum and zinc oxide-based nanolubricants. 
October 3, 2016

\section{TEST LIQUIDS}

Eleven nanolubricants were made by a manufacturer using a proprietary, polymeric surfactant ${ }^{2}$ along with a commercial polyolester lubricant (RL32-3MAF) ${ }^{3}$. The RL32-3MAF is commonly used with R134a chillers and has a nominal liquid kinematic viscosity of $31.2 \mathrm{~mm}^{2} \cdot \mathrm{s}^{-1}$ at $313.15 \mathrm{~K}$. Two different nanoparticle materials were used, $\mathrm{Al}_{2} \mathrm{O}_{3}$ and $\mathrm{ZnO}$, having different surface-area weighted diameters $\left(D_{\mathrm{p}}\right)$ : nominally $40 \mathrm{~nm}$ and $20 \mathrm{~nm}$, respectively. The surfactant and the nanoparticle mass fractions were varied to provide the eleven different nanolubricants for test. All of the test nanolubricants were ultrasonically mixed for approximately $24 \mathrm{~h}$ prior to measurement.

Figure 1 shows Transmission Electron Microscopy (TEM) images of the $\mathrm{ZnO}$ nanoparticles and the $\mathrm{Al}_{2} \mathrm{O}_{3}$ nanoparticles as taken by Sarkas $(2014,2015)$. The manufacturer states the size of the $\mathrm{ZnO}$ nanparticle and the $\mathrm{Al}_{2} \mathrm{O}_{3}$ nanoparticle as $20 \mathrm{~nm}$ and $40 \mathrm{~nm}$, respectively, based on the surface-area, which were derived from specific surface area measurements. Knowledge of the surface-area weighted size is useful for determining the amount of surfactant necessary to produce a stable dispersion; however, number-weighted sizes more closely represent the actual projected dimension of the nanoparticle for non-spherical geometries. As shown in Fig. 1, the $\mathrm{ZnO}$ nanoparticle has both spherical and elongated structures that form tetrapods (Sarkas, 2015), while the $\mathrm{Al}_{2} \mathrm{O}_{3}$ nanoparticles appear more spherical.

\footnotetext{
${ }^{2}$ Due to the proprietary nature of the surfactant (Nanophase Technologies R\&D product code R1103RL32-3MAF), no property information can be provided here.

${ }^{3}$ Certain commercial equipment, instruments, or materials are identified in this paper in order to specify the experimental procedure adequately. Such identification is not intended to imply recommendation or endorsement by the National Institute of Standards and Technology, nor is it intended to imply that the materials or equipment identified are necessarily the best available for the purpose.
} 
October 3, 2016

The number-weighted sizes of the nanoparticles in the nanolubricant were measured with a Dynamic Light Scattering (DLS) technique using a $633 \mathrm{~nm}$ wavelength laser and a sieving technique using a syringe filter. An index of refraction of 1.67 and 2.00 for $\mathrm{Al}_{2} \mathrm{O}_{3}$ and $\mathrm{ZnO}$, respectively, was used in the Brownian motion-based calculation that was done internally by the DLS instrument for the particle size. The uncertainty of the packaged DLS instrumentation was confirmed with a NIST-traceable $60 \mathrm{~nm} \pm 2.7 \mathrm{~nm}$ nanofluid standard. The measured diameter of the standard with the DLS system was $64 \mathrm{~nm} \pm 5 \mathrm{~nm}$, which coincides with the range of uncertainty of the standard. The DLS measurements showed that the average equivalent diameters on a number-weighted bases for the $\mathrm{Al}_{2} \mathrm{O}_{3}$ and the $\mathrm{ZnO}$ nanoparticles were $127 \mathrm{~nm} \pm 3 \mathrm{~nm}$ and $135 \mathrm{~nm} \pm 3 \mathrm{~nm}$, respectively. Figure 2 shows representative size distributions by number-weighted bases for the two nanolubricants. The width of the distribution at half of the peak number percentage was approximately $32 \mathrm{~nm}$ and $41 \mathrm{~nm}$ for the $127 \mathrm{~nm}$ diameter and the $135 \mathrm{~nm}$ diameter nanoparticles, respectively. The difference between the DSL nanoparticle sizing and that of the manufacturer are due in part to some agglomeration ${ }^{4}$ within the nanolubricant, but are primarily due to the difference between number-weighted and surface-weighted sizing. This is particularly true for the $\mathrm{ZnO}$ nanoparticle where the DLS measurement produces the diameter of the overall structure because it is an optical measurement that "sees" the projected dimension of the nanoparticle structure. Consequently, the DLS technique yields the overall dimension of the $\mathrm{ZnO}$ tetrapod. For viscosity measurements, the projected area is more germane than the surface area for the same reason that the profile drag is generally larger than the skin friction for fluid flow.

\section{PROPERTY MEASUREMENTS}

$\underline{\text { Rotational Viscometer }}$

A Stabinger-type viscometer (Anton-Parr SVM 3000) was used to measure the dynamic viscosity and the density of the liquid nanolubricant at seven temperatures between approximately $288 \mathrm{~K}$ and

\footnotetext{
${ }^{4}$ No particle settling was observed for the approximate month of testing and the dispersion was believed to be stable
} 
October 3, 2016

$318 \mathrm{~K}$. This temperature range covers all but the low temperature (down to $277.6 \mathrm{~K}$ ) that would be applicable to water chillers and is controlled by a Peltier thermostat, which is internal to the viscometer. The measurements were made at atmospheric pressure at an approximate altitude of $137 \mathrm{~m}$ above sea level (Gaithersburg, Maryland, USA).

The operation principle of the Stabinger-type viscometer relies on rotating concentric cylinders. The liquid sample is contained in the annulus of a concentric cylinder where the inner cylinder is hollow and of less mass than the sample. This allows the inner cylinder to float freely and be centered by centrifugal forces in the sample when the outer cylinder is spun by a rotating magnetic field. Viscous shear forces on the liquid transfer the rotation to the inner cylinder. Measurements on the inner cylinder are used to calculate the difference in speed and torque between the outer and inner cylinder, and thus, the dynamic viscosity. The viscometer uses a vibrating U-tube to determine the density. The kinematic viscosity reported here is obtained by dividing the dynamic viscosity by the density. Wasp et al. (1977) have recommended concentric cylinder viscometers for use with both Newtonian and non-Newtonian solid-liquid suspensions.

Mahbubul et al. (2012) acknowledge research that shows that nanofluids can be either Newtonian or non-Newtonian. For a particular fluid and temperature, a non-Newtonian fluid requires knowledge of the applied shear rate in order to characterize the viscosity, while a Newtonian fluid does not, i.e., the viscosity of a Newtonian fluid is independent of the shear rate. In his pioneering work, Bingham (1916) chose to investigate clay suspensions because they behaved in a non-Newtonian way. Shima et al. (2009) believe that non-Newtonian behavior is a characteristic of an unstable nanofluid. Considering that Bingham (1916) prepared the clay suspensions by "thoroughly 
October 3, 2016

[shaking]" and that the samples exhibited "settling" shortly after being prepared, the suspensions were unstable, which is consistent with the observation of Shima et al. (2009). For the present study, the shear rates for the neat-lubricant and all the nanolubricants (Quine, 2015), lie on the same curve when plotted against viscosity. This indicates a Newtonian behavior due to the absence of a shear induced hysteresis effect (Green, 1949) that would have caused a non-Newtonian fluid to deviate from the curve. In addition, Kedzierski (2013) has verified the Newtonian behavior for similar metal-oxide nanolubricants by corroborating measurements with a glass Cannon-Fenske routine viscometer.

The literature that shows that a nanofluid can transition from a Newtonian fluid to a non-Newtonian fluid at critical shear rate is conflicting (Meyer et al., 2016). For example, the nanolubricants of Hernandez Battez et al. (2014) were Newtonian for shear rates less than $700 \mathrm{~s}^{-1}$ and non-Newtonian for significantly larger shear rates $\left(10^{6} \mathrm{~s}^{-1}\right.$ to $\left.10^{7} \mathrm{~s}^{-1}\right)$. Conversely, all of Tseng and Lin (2003) water-based nanofluids exhibited non-Newtonian behavior for shear rates less than $700 \mathrm{~s}^{-1}$ and one of them showed Newtonian behavior for shear rates larger than $700 \mathrm{~s}^{-1}$. The present data is for shear rates less than $400 \mathrm{~s}^{-1}$ (Quine, 2015). Notwithstanding the lack of viscosity measurements at larger shear rates for the present data, the authors side with Shima et al. (2009) and believe that a stable nanofluid should behave as a Newtonian fluid.

\section{Thermal Conductivity}

The thermal conductivity $(k)$ of the test fluids was measured using a commercially available transient hot wire (THW) that was immersed in the liquids. Over half of the researchers that contributed thermal conductivity measurements to the Buongiorno et al. (2009) study used this type of instrument. The THW technique relies on the thermal response of the liquid to a temperature 
October 3, 2016

spike of the $1.3 \mathrm{~mm}$ diameter and $60 \mathrm{~mm}$ long wire caused by a current spike, which induces resistance heating. The short duration of the heat pulse ensured that natural convection from the wire was negligible (Nasiri et al., 2011). The variation in the wire-resistance permits the change in the wire temperature with respect to time to be monitored. A properly designed THW behaves as a finite portion of an infinite line heat source by nearly pure radial conduction (Healy et al., 1976). For this case, the thermal conductivity is proportional to the instantaneous wire heat flux and inversely proportional to the gradient of the temperature with respect to the natural logarithm of time.

\section{$\underline{\text { Uncertainties }}$}

The viscometer manufacturer-quoted uncertainties for the $95 \%$ confidence level for kinematic viscosity, density, and temperature were $\pm 0.35 \%, \pm 0.5 \mathrm{~kg} \cdot \mathrm{m}^{-3}$, and $\pm 0.02 \mathrm{~K}$, respectively. The viscometer was used to measure the density and viscosity of a calibration fluid with a nominal viscosity and density at $293.15 \mathrm{~K}$ of $1320 \mathrm{~mm}^{2} \cdot \mathrm{s}^{-1}$ and $845.4 \mathrm{~kg} \cdot \mathrm{m}^{-3}$, respectively. Residuals between the measurements and the calibration fluid over the same temperature range of this study were within specifications quoted by the manufacturer.

The expanded uncertainties for the kinematic viscosity $\left(U_{v}\right)$ and density $\left(U_{\rho}\right)$ measurements for each fluid were calculated by combining the manufacturer quoted uncertainty with the standard uncertainties of the regressions for each fluid with a coverage factor. All uncertainties given in this manuscript are for the $95 \%$ confidence level unless otherwise stated. As Table 1 shows for all of the data sets, the expanded uncertainty in density $\left(U_{\rho}\right)$ was within $\pm 0.26 \%$ of the measurement. Table 2 shows that the uncertainty in the kinematic viscosity, for a given data set, varies between $\pm 0.38 \%$ and $\pm 2.25 \%$. The average $U_{v}$ is approximately $\pm 0.95 \%$. The uncertainty of the 
October 3, 2016

nanoparticle mass fractions $\left(x_{\mathrm{np}}\right)$, the surfactant mass fractions $\left(x_{\mathrm{s}}\right)$, and the lubricant mass fractions $\left(x_{\mathrm{L}}\right)$ were approximately $\pm 0.02 \%$.

For the thermal conductivity measurements, the manufacturer reports an uncertainty of $\pm 5 \%$ from $0.2 \mathrm{Wm}^{-1} \mathrm{~K}^{-1}$ to $2 \mathrm{Wm}^{-1} \mathrm{~K}^{-1}$ and $\pm 0.01 \mathrm{Wm}^{-1} \mathrm{~K}^{-1}$ from $0.02 \mathrm{Wm}^{-1} \mathrm{~K}^{-1}$ to $0.2 \mathrm{Wm}^{-1} \mathrm{~K}^{-1}$.

\section{RESULTS}

\section{Density}

Figures 3 and 4 show the measured mixture density $\left(\rho_{\mathrm{m}}\right)$ of the nanolubricant mixtures versus temperature $(T)$ at atmospheric pressure for the $\mathrm{Al}_{2} \mathrm{O}_{3}$ and the $\mathrm{ZnO}$ nanoparticles, respectively. The solid lines shown in Figs. 3 and 4 are linear best-fit regressions or estimated means of the data. Forty-two of the 840 measurements were removed before fitting because they were identified as "outliers" based on having both high influence and high-leverage (Belsley et al., 1980). Table 1 gives the constants for the linear regression of the measured specific volume $\left(\rho_{\mathrm{m}}^{-1}\right)$ versus the measured temperature for the fluids tested. The dashed lines on either side of the mean represent the lower and upper $95 \%$ simultaneous (multiple-use) confidence intervals for the mean. These dashed lines are difficult to see on the figures because they nearly coincide with the mean values. The last column of Table 1 provides the residual standard deviation of each fit. Equation (1) shows the recommended mixture equation for the density of suspensions, $\rho_{\mathrm{m}}$ (Wasp et al., 1977):

$$
\frac{1}{\rho_{\mathrm{m}}}=\frac{x_{\mathrm{s}}}{\rho_{\mathrm{s}}}+\frac{x_{\mathrm{L}}}{\rho_{\mathrm{L}}}+\frac{x_{\mathrm{np}}}{\rho_{\mathrm{np}}}
$$

Using the density of $\mathrm{Al}_{2} \mathrm{O}_{3}\left(\rho_{\mathrm{np}}=3600 \mathrm{~kg} \cdot \mathrm{m}^{-3}\right)$ and $\mathrm{ZnO}$ nanoparticles $\left(\rho_{\mathrm{np}}=5610 \mathrm{~kg} \cdot \mathrm{m}^{-3}\right)$ as reported by Sarkas $(2014,2015)$, the fitted values for $\rho_{\mathrm{L}}$ from Table 1 , and the mass fractions corresponding to those of the measured nanolubricant, resulted in deviations from eq. (1) between 
October 3, 2016

$1 \%$ and $6 \%$ for the $\mathrm{Al}_{2} \mathrm{O}_{3}$ based nanolubricants and $-1 \%$ and $-4 \%$ for the $\mathrm{ZnO}$ based nanolubricants. Backsubstituting the measurements into eq. (1) and solving for the surfactant specific volume resulted in the following approximate fit: $1 / \rho_{\mathrm{s}}=0.0005840\left[\mathrm{~kg}^{-1} \cdot \mathrm{m}^{3}\right]+$ $0.0003240\left[\mathrm{~kg}^{-1} \cdot \mathrm{m}^{3}\right] T_{\mathrm{r}}$ (where $T_{\mathrm{r}}$ is the nanolubricant temperature normalized by $273.15 \mathrm{~K}$, i.e., $\left.T_{\mathrm{r}}=T / 273.15 \mathrm{~K}\right)$. The deviations increased with increasing nanoparticle mass fraction, but the residuals did not exhibit temperature dependence, suggesting that at least part of the uncertainty may be due to uncertainties associated with the mass fraction. The differing agreement with respect to eq. (1) exhibited by the $\mathrm{Al}_{2} \mathrm{O}_{3}$ and the $\mathrm{ZnO}$ nanolubricants may possibly be caused by the difference in the structure and size of the nanoparticles as Grassian (2008) and Jamison et al. (2008) have discussed.

\section{VISCOSITY MEASUREMENTS}

Figures 5 and 6 show the measured kinematic viscosity $(v)$ of the nanolubricant mixtures versus temperature $(T)$ at atmospheric pressure for the $\mathrm{Al}_{2} \mathrm{O}_{3}$ and $\mathrm{ZnO}$ based nanolubricants, respectively. The solid lines shown in the figures are three-parameter best-fit regressions or estimated means of the data to the following form for the normalized viscosity $\left(v / v_{\mathrm{o}}\right)$,

$$
\frac{v}{v_{0}}=\exp \left(\mathrm{A}_{0}+\frac{\mathrm{A}_{1}}{T_{r}}+\mathrm{A}_{2} \ln \left(T_{r}\right)+\mathrm{A}_{3} T_{r}^{\mathrm{A}_{4}}\right)
$$

where $v_{\mathrm{o}}$ is the unity-viscosity $\left(v_{\mathrm{o}}=1 \mathrm{~mm}^{2} \cdot \mathrm{s}^{-1}\right)$. This form was successfully used for 1944 compounds in the DIPPR Project 801 database (Rowley et al., 2007). The term with the $\mathrm{A}_{3}$ leading constant was found not to be statistically significant for the present data set and was not used. In addition, 34 of the 840 measurements were removed before fitting because they were identified as "outliers" based on having both high influence and high-leverage (Belsley, et al., 1980). Table 2 gives the constants for the regression of the normalized kinematic viscosity versus the normalized temperature to eq. (2) for the fluids tested here. The dashed lines in Figs. 5 and 6 on either side of 
October 3, 2016

the mean represent the lower and upper $95 \%$ simultaneous (multiple-use) confidence intervals for the mean and is roughly equal to the $U_{v}$ given in Table 2 .

\section{DATA CORRELATION/MODEL COMPARISON}

This section presents the nanolubricant density fit and comparison of the measured nanolubricant kinematic viscosity and thermal conductivity to existing models. The existing models are a function of temperature, nanoparticle mass fraction $\left(x_{\mathrm{np}}\right)$, surfactant mass fraction, and nanoparticle size.

Thermal Conductivity

The measured nanolubricant thermal conductivities $\left(k_{\mathrm{nL}}\right)$ were compared to the heterogeneous media model for spherical and well dispersed particles that is attributed to Maxwell (1954):

$$
k_{\mathrm{nL}}=\frac{k_{\mathrm{np}}+2 k_{\mathrm{L}}+2 \phi\left(k_{\mathrm{np}}-k_{\mathrm{L}}\right)}{k_{\mathrm{np}}+2 k_{\mathrm{L}}-\phi\left(k_{\mathrm{np}}-k_{\mathrm{L}}\right)} k_{\mathrm{L}}
$$

where the thermal conductivity of the nanoparticle $\left(k_{\mathrm{np}}\right)$, the thermal conductivity of the pure lubricant $\left(k_{\mathrm{L}}\right)$ and the volume fraction of the nanoparticles in the nanolubricant $(\phi)$ are inputs to eq. (3). The actual equation that Maxwell (1954) developed was for electrical resistivity rather than thermal conductivity. Somewhere along the way, someone used the Wiedemann-Franz law (Tipler, 1978) to translate Maxwell's development to eq. (3). Because of this, a further restriction on the above model, beyond spherical particles, is how well the thermal conductivities of both the base fluid and the nanoparticle remain linearly related to their electrical resistivities as dictated by the Wiedemann Franz law (Tipler, 1978). One could imagine that if the relationship between resistivity and thermal conductivity varies in the same non-linear way for the nanoparticle as it does for the base fluid that this effect would cancel and eq. (3) would still be valid for this case. 
Figure 7 compares the measured nanolubricant thermal conductivities to the Maxwell equation as solid lines. The Maxwell equation predicts the $\mathrm{Al}_{2} \mathrm{O}_{3}$ nanolubricant data to within $\pm 1 \%$ of the measurements; however, it underpredicts the $\mathrm{ZnO}$ nanolubricant thermal conducitivities by roughly $70 \%$. The failure of the Maxwell equation to predict the $\mathrm{ZnO}$ nanolubricant measurements could be due to the non-spherical $\mathrm{ZnO}$ nanoparticles or because $\mathrm{ZnO}$ does not follow the Wiedemann Franz law (Tipler, 1978) as $\mathrm{Al}_{2} \mathrm{O}_{3}$ does. Hamilton and Crosser (1962) modified Maxwell's equation with the sphericity ( $\Psi$ ) so that it would be valid for nonspherical particles:

$$
k_{\mathrm{nL}}=\frac{k_{\mathrm{np}}+\left(\frac{3}{\Psi}-1\right) k_{\mathrm{L}}+\left(\frac{3}{\Psi}-1\right) \phi\left(k_{\mathrm{np}}-k_{\mathrm{L}}\right)}{k_{\mathrm{np}}+\left(\frac{3}{\Psi}-1\right) k_{\mathrm{L}}-\phi\left(k_{\mathrm{np}}-k_{\mathrm{L}}\right)} k_{\mathrm{L}}
$$

The sphericity is defined as the ratio of the surface area of a particle-volume-equivalent sphere to the actual surface area of the particle (Clift et al., 1978). A tetrahedron has a sphericity of approximately 0.67 . It is likely that the tetrapod-shaped $\mathrm{ZnO}$ nanoparticle would have a smaller sphericity than a similar geometry with continuous, flat sides. Considering this, when the sphericity is set to 0.55 , as shown by the dashed line in Fig. 7, eq. (4) predicts the $\mathrm{ZnO}$ nanolubricant thermal conductivity measurements to within $\pm 1 \%$. Consequently, it is believed that the failure of the Maxwell equation to predict the thermal conductivity for the $\mathrm{ZnO}$ nanolubricant was primarily due to the non-spherical shape of the $\mathrm{ZnO}$ nanoparticle.

\section{$\underline{\text { Viscosity }}$}

The measured nanolubricant viscosities were compared to the viscosity model of Kedzierski (2013) shown in eqs. (5) through (7) below. The viscosity model sums the component kinematic 
October 3, 2016

viscosities of the nanoparticle, the surfactant and the base lubricant. The mass-fraction-weighted sum of the natural log of the component kinematic viscosities:

$$
\ln v_{\mathrm{m}}=x_{\mathrm{L}}^{1.25} \ln v_{\mathrm{L}}+x_{\mathrm{np}}^{1.25} \ln v_{\mathrm{np}}+x_{\mathrm{s}}^{1.25} \ln v_{\mathrm{s}}
$$

Equation (5) is nearly the same as the equation recommended by Reid et al. (1977) with the exception that the exponents on the mass fractions for Reid et al. (1977) are 1 rather than 1.25. For eq. (5), the liquid kinematic viscosity of the nanolubricant is $v_{\mathrm{m}}$. The kinematic viscosity of the base lubricant $\left(v_{\mathrm{L}}\right)$ is determined from the equation and coefficients given in Table 1 for $x_{\mathrm{L}}=1$. The kinematic viscosities of the surfactant $\left(v_{\mathrm{s}}\right)$ and that of the $\mathrm{Al}_{2} \mathrm{O}_{3}$ nanoparticle ( $\left.v_{\mathrm{np}}\right)$ for eq. (5) are given as:

$\ln v_{\mathrm{s}}=0.149 D_{\mathrm{p}}[\mathrm{nm}]-87.2079+\frac{7.1353}{T_{\mathrm{r}}^{-66.12}+0.074}$

$\ln v_{\mathrm{np}}=\left(1.426-0.0071 D_{\mathrm{p}}[\mathrm{nm}]\right)\left(4.7356+\frac{1.4706}{T_{\mathrm{r}}^{4.05}-1.11}\right)$

where the kinematic viscosity has units of $\mathrm{mm}^{2} \cdot \mathrm{s}^{-1}$, and the diameter of the nanoparticle $\left(D_{\mathrm{p}}\right)$ has units of nm.

The model assumes that a good dispersion exists whereby the surfactant is more closely associated with the nanoparticle than it is with the base lubricant. Equations 5 and 6 do not represent the viscosities of the pure surfactant and the nanoparticles, respectively. Rather, as evidenced by the $D_{\mathrm{p}}$ term, they are pseudo-viscosities that each account for the interaction between the nanoparticle and 
October 3, 2016

the surfactant. This interaction is consistent with the observations of Grassian (2008) and Jamison et al. (2008) who have shown that fundamental properties can be size dependent on the nanoscale.

For surfactant mass fractions less than $4 \%$, the above model predicted the viscosities for all the nanolubricants to within roughly $\pm 20 \%$. However, for the largest surfactant mass fraction of approximately $12 \%$, the model predictions remained only within $\pm 40 \%$ of the measurements. The reason for the model disagreement was believed to be the use of a different surfactant between the present study and the one used by Kedzierski (2013). Consequently, the surfactant viscosity was refitted to the present dataset as:

$$
\ln v_{\mathrm{s}}=0.149 D_{\mathrm{p}}[\mathrm{nm}]+10.431-\frac{0.396}{0.0512-T_{\mathrm{r}}^{-66.12}}
$$

Figure 8 shows the comparison of the measured kinematic viscosity for the liquid nanolubricant to the predictions that were obtained from eq. (5) with eqs. (7) and (8) as input. Ninety-seven percent of the viscosities for all of the mixtures (including both nanoparticle sizes) are predicted to within $\pm 20 \%$ of the measurement.

\section{CONCLUSIONS}

Liquid kinematic viscosity, liquid density, and liquid thermal conductivity measurements of synthetic polyolester (chiller lubricant) based aluminum oxide $\left(\mathrm{Al}_{2} \mathrm{O}_{3}\right)$ and zinc oxide $(\mathrm{ZnO})$ nanoparticle nanolubricants (dispersions) have been measured at atmospheric pressure and for a temperature range from approximately $288 \mathrm{~K}$ to $318 \mathrm{~K}$. Two different nanoparticles sizes were studied, which were well dispersed by a surfactant in a commercially available polyolester, chiller lubricant. Viscosity, density and thermal conductivity measurements were made for the pure base 
October 3, 2016

lubricant along with eleven nanolubricants with differing nanoparticle and surfactant mass fractions. The liquid viscosity, density and thermal conductivity were shown to increase with respect to increasing nanoparticle mass fraction. The liquid viscosity, and the density were shown to decrease with respect to increasing temperature.

The measurements were compared to existing models. The agreement varied with temperature, nanoparticle mass fraction, surfactant mass fraction, and nanoparticle diameter. An existing model was used to predict the viscosity of the nanolubricant within $\pm 20 \%$ by modifying it so that it was valid for the particular surfactant of this study. Maxwell's expression for thermal conductivity was shown to work well $( \pm 1 \%$ ) for the nanolubricants with spherical nanoparticles, but not for the ones with non-spherical nanoparticles. However, the Hamilton-Crosser model predicted the thermal conductivity of the nanolubricants with non-spherical nanoparticles to within $\pm 1 \%$ by using a sphericity of 0.55 . The specific volume of the nanolubricants were predicted to within $\pm 6 \%$ by using a linearly weighted mass fraction mixing rule.

\section{ACKNOWLEDGEMENTS}

This work was funded jointly by NIST and CUA. Thanks go to the following NIST personnel for their constructive criticism of the manuscript: P. Domanski, A. Persily, and A. Pertzborn. In addition, comments from M. Carr of the United States Naval Academy were also greatly appreciated. The author extends appreciation to Mr. W. Guthrie and Mr. A. Heckert of the NIST Statistical Engineering Division for their consultations on the uncertainty analysis. The nanolubricants were manufactured especially for NIST by Nanophase Technologies. 
October 3, 2016

\section{REFERENCES}

Belsley, D. A., Kuh, E., and Welsch, R. E., 1980, Regression Diagnostics: Identifying Influential Data and Sources of Collinearity, Wiley, NY.

Bingham, E. C., 1916, “An Investigation of the Laws of Plastic Flow,” Bulletin of the Bureau of Standards, 13(2), 309-353.

Buongiorno, J., et al., 2009, “A Benchmark Study on the Thermal Conductivity of Nanofluids,” Journal of Applied Physics, 106, 094312.

Bi, S., Shi, L., and Zhang, L., 2007, Application of Nanoparticles in Domestic Refrigerators, Applied Thermal Engineering, 28, 1834-1843.

Clift, R., Grace, J. R., and Weber, M. E., 1979, Bubbles, Drops, and Particles, Academic Press, NY, p. 20 .

Eastman, J. A, Choi, S. U. S., Li, S., Yu, W., and Thompson, L. J., 2001, “Anomalously Increased Effective Thermal Conductivities of Ethylene Glycol-Based Nanofluids Containing Copper Nanoparticles," Appl. Phys. Lett. 78, 718-720.

Grassian, V. H., 2008, When Size Really Matters: Size-Dependent Properties and Surface Chemistry of Metal and Metal Oxide Nanoparticles in Gas and Liquid Phase Environments, J. Phys. Chem. C, 112 (47), 18303-18313. 
October 3, 2016

Green, H. 1949. Industrial Rheology and Rheological Structures, Wiley, NY.

Hamilton, R.L., Crosser, O.K., 1962, Thermal Conductivity of Heterogeneous Two-Component Systems, Ind. Eng. Chem. Fundamen., 1 (3), 187-191.

Healy, J.J. de Groot, J.J, and Kestin, J., 1976, The theory of the transient hot-wire method for measuring thermal conductivity, Physica 82C, North-Holland Publishing Co., 392-408 .

Henderson, K., Park, Y., Liu, L., Jacobi, A. M., 2010, “Flow-Boiling Heat Transfer of R-134aBased Nanofluids in a Horizontal Tube," IJHMT, 53, 944-951.

Hernandez Battez, A., Viesca, J. L., Gonzalez, R., Garcia, A., Reddyhoff, T., and Higuera-Garrido, A., 2014, Effect of Shear Rate, Temperature, and Particle Concentration on the Rheological Properties of $\mathrm{ZnO}$ and ZrO2 Nanofluids, Tribology Transactions, 57(3), 489-495.

Jamison, J. A., Krueger, K. M., Yavuz, C. T., Mayo, J. T., LeCrone, D., Redden, J. J., and Colvin, V. L., 2008, Size-Dependent Sedimentation Properties of Nanocrystals, ACS Nano, 2 (2), 311-319.

Kedzierski, M. A., and Fick, S. E., 2015, "Effect of Acoustic Excitation on R134a/ $/ \mathrm{Al}_{2} \mathrm{O}_{3}$

Nanolubricant Mixture Boiling on a Reentrant Cavity Surface," J. Heat Transfer, 137(11):111503111503-9. HT-14-1601 
October 3, 2016

Kedzierski, M. A., 2013, “Viscosity and density of aluminum oxide nanolubricant, ” International Journal of Refrigeration," 36(4):1333-1340.

Kedzierski, M. A., 2012, "R134a/A1O Nanolubricant Mixture Pool Boiling on a Rectangular Finned Surface," ASME Journal of Heat Transfer, 134, 121501.

Kedzierski, M. A., 2011, "Effect of $\mathrm{Al}_{2} \mathrm{O}_{3}$ Nanolubricant on R134a Pool Boiling Heat Transfer," Int. J. Refrigeration, 34 (2), 498-508.

Kedzierski, M. A., and Gong, M., 2009, "Effect of CuO Nanolubricant on R134a Pool Boiling Heat Transfer," Int. J. Refrigeration, 25, 1110-1122.

Kedzierski, M. A., 2008, Effect of CuO Nanoparticle Concentration on R134a/Lubricant Pool Boiling Heat Transfer, ASME Journal of Heat Transfer for the Special Issue of MNHT08, 131, 043205.

Kedzierski, M. A., 2001, The Effect of Lubricant Concentration, Miscibility and Viscosity on R134a Pool Boiling, Int. J. Refrigeration 24 (4), 348-366. 
October 3, 2016

Mahbubul, I.M., Saidur R., Amalina M.A., 2012, “Latest developments on the viscosity of nanofluids", International Journal of Heat and Mass Transfer 55, 874-885.

Maxwell, J. C., 1954, "A Treatise on Electricity and Magnetism,” Vol. 1, 3rd ed. Dover, NY, p. 440.

Meyer, J. P., Adio, S. A., Sharifpur, M., and Nwosu, P. N., 2016. The viscosity of nanofluids: A review of the theoretical, empirical, and numerical models. Heat Transfer Engineering 37, 387-421.

Nasiri, A., Shariaty-Niasar, M., Rashidi, A., Amrollahi, A., and Khodafarin, R., 2011, "Effect of dispersion method on thermal conductivity and stability of nanofluid," Experimental Thermal and Fluid Science, 35(4):717-723.

Pramod Warrier1 and Amyn Teja corresponding author1 2011 Effect of particle size on the thermal conductivity of nanofluids containing metallic nanoparticles http://www.ncbi.nlm.nih.gov/pmc/articles/PMC3211308/

Quine, K., 2015, “Thermophysical Property Measurements for Aluminum Oxide and Zinc Oxide Based Nanolubricants," Masters Thesis The Catholic University of America. 
October 3, 2016

Reid, R. C, Prausnitz, J. M., and Sherwood, T. K., 1977, The Properties of Gases and Liquids, $3^{\text {rd }}$ ed., McGraw-Hill, New York, p. 460.

Rowley, R. L., Wilding, W. V., Oscarson, J. L., 2007, DIPPR Project 801 Data Compilation of Pure Compound Properties; March 2007 ed.; AIChE Design Institute for Physical Properties: New York, http://DIPPR.BYU.edu.

Sarkas, H., 2014, 2015, Private Communications, Nanophase Technologies Corporation, Romeoville, IL.

Shima, P. D., Philip, J., and Raj, B. 2009. Magnetically Controllable Nanofluid with Tunable Thermal Conductivity and Viscosity, Applied Physics Letters, 95(13), 133112.

Tipler, P. L., 1978, Modern Physics, Worth Pub, NY, p. 320.

Tao, X., Jiazheng, Z., and Kang, X., 1996, “The ball-bearing effect of diamond nanoparticles as an oil additive,” J. Phys. D: Appl. Phys. 29, 2932-2937.

Tseng, W. J., and Lin, K., 2003, Rheology and Colloidal Structure of Aqueous TiO2 Nanoparticle Suspensions, Materials Science and Engineering: A, 355, 186-192. 
October 3, 2016

Venerus, D., et al., 2010, "Viscosity Measurements On Colloidal Dispersions (Nanofluids) For Heat

Transfer Applications,” Applied Rheology Journal, 20(4), 44582.

Wasp, E. J., Kenny, J. P., Gandhi, R. L., 1977, Solid-Liquid Flow Slurry Pipeline Transportation, Series on Bulk Materials Handling 1 (4), 56-58. 


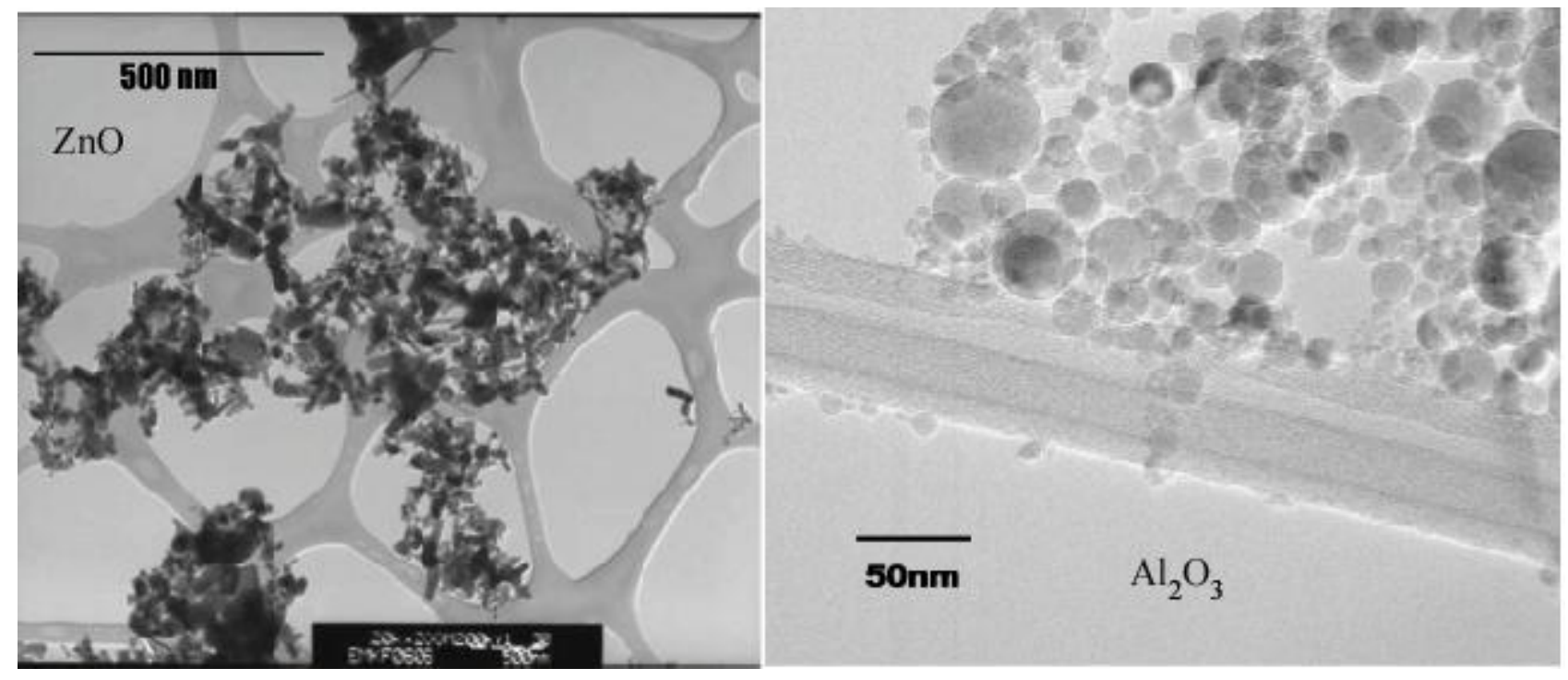

Fig. 1 TEMs of $\mathrm{ZnO}$ and $\mathrm{Al}_{2} \mathrm{O}_{3}$ nanolubricants and substrates on which the particles are deposited (Sarkas, 2014, 2015). 


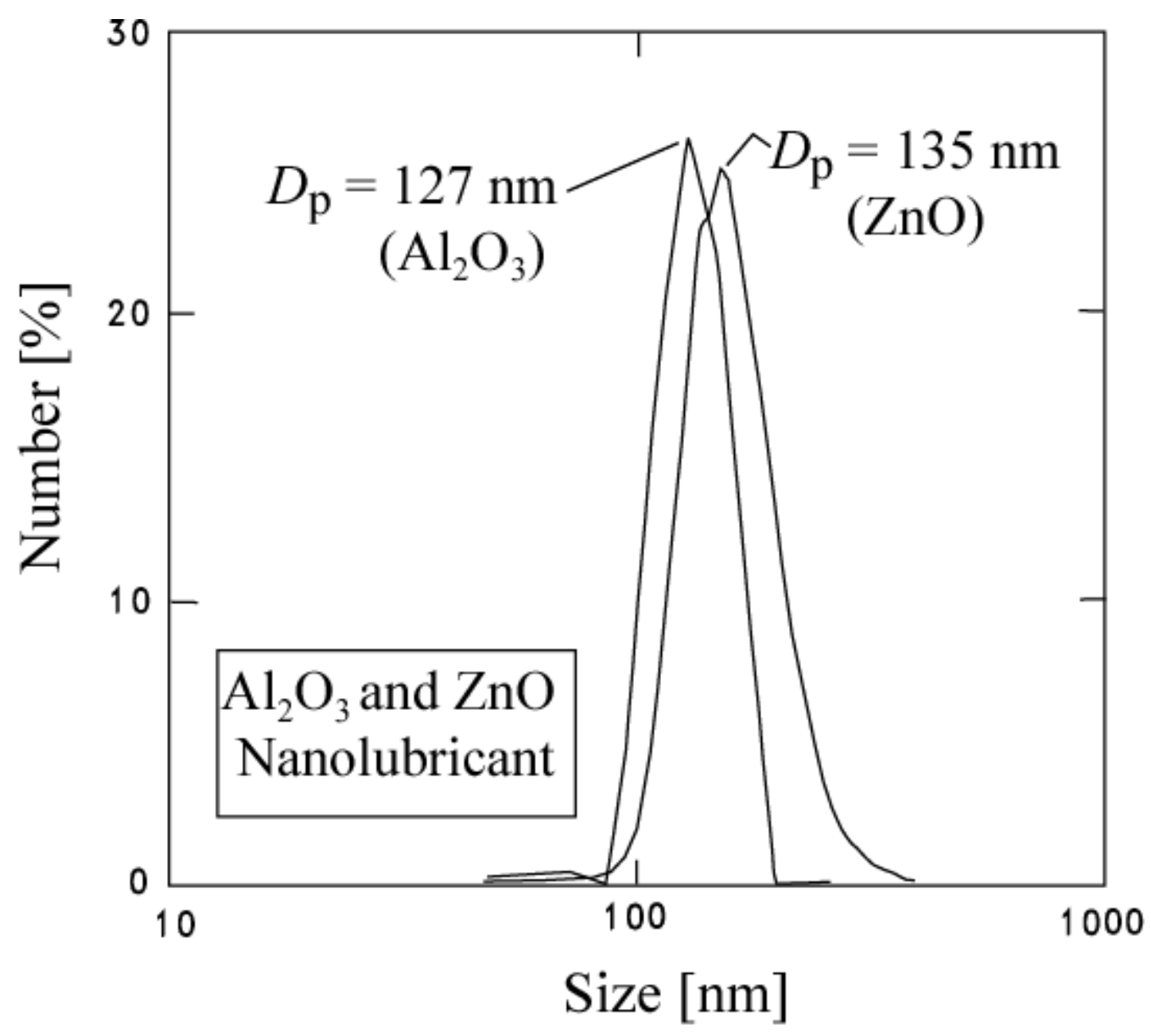

Fig. 2 Representative size distributions by number-weighted bases for the $127 \mathrm{~nm}$ and the $135 \mathrm{~nm}$ diameter nanolubricants. 


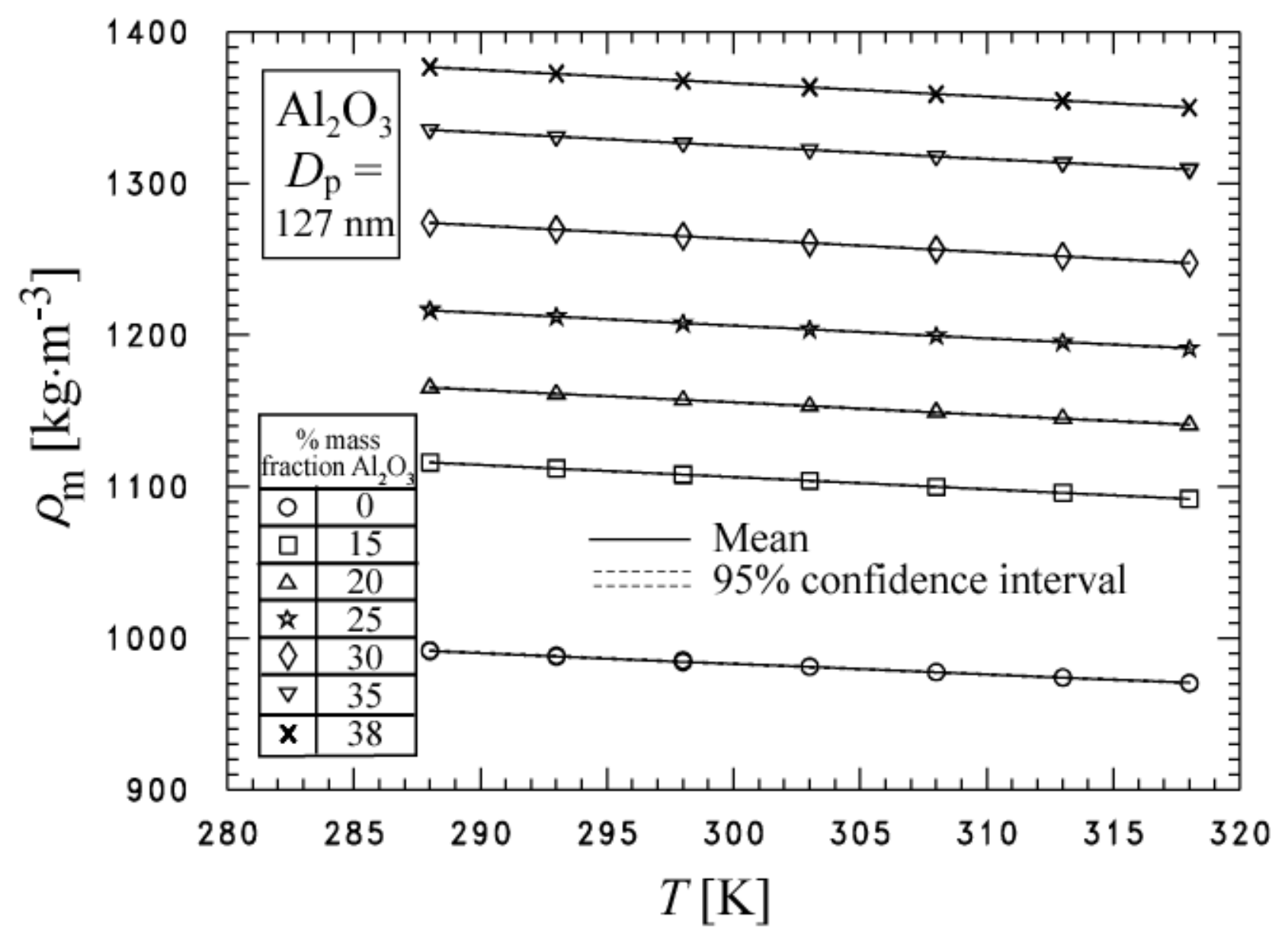

Fig. 3 Measured liquid density of $\mathrm{Al}_{2} \mathrm{O}_{3}$ nanolubricant with $127 \mathrm{~nm}$ diameter nanoparticles for various mass fractions at atmospheric pressure. 


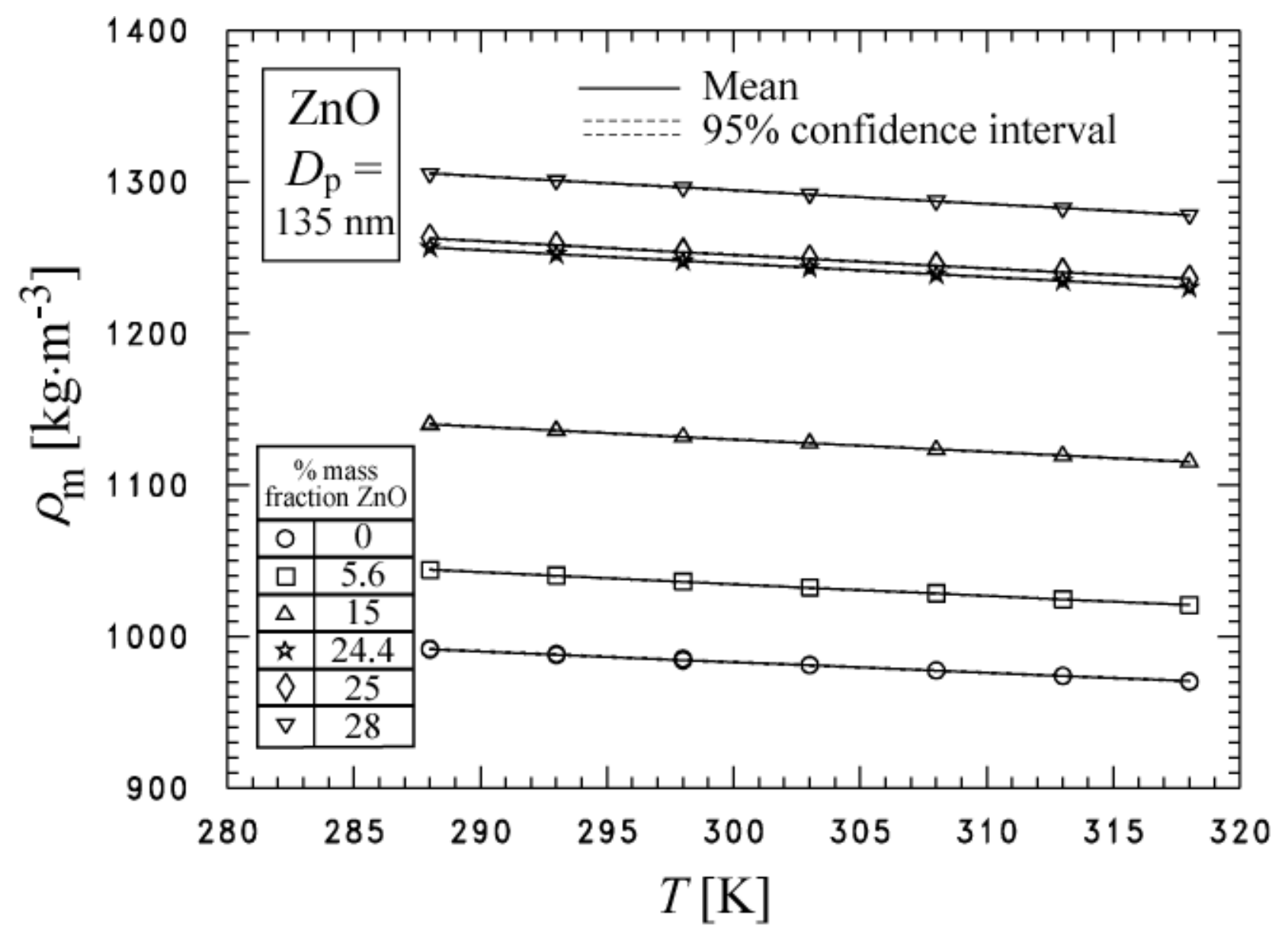

Fig. 4 Measured liquid density of $\mathrm{ZnO}$ nanolubricant with $135 \mathrm{~nm}$ diameter nanoparticles for various mass fractions at atmospheric pressure. 


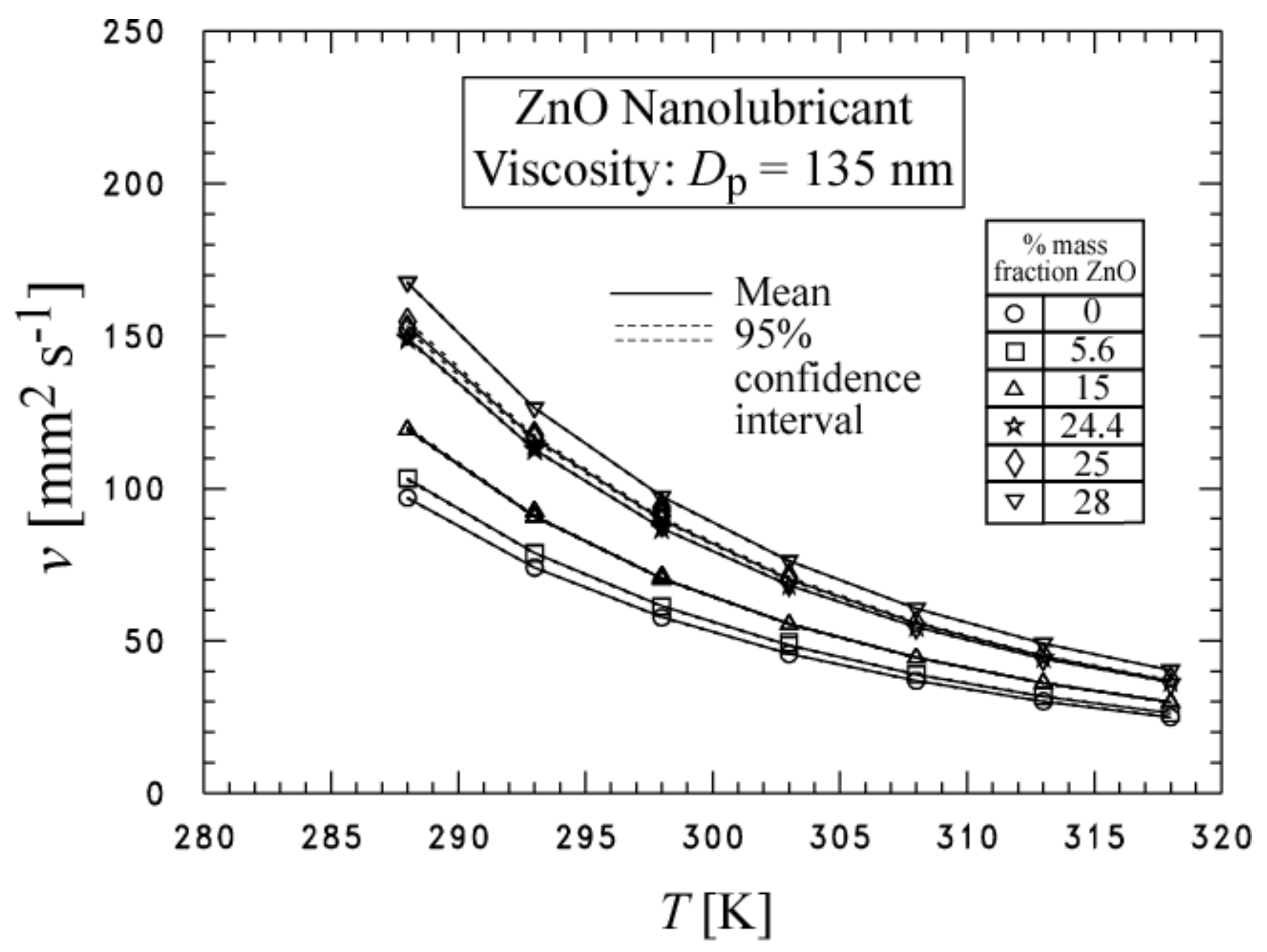

Fig. 5 Measured liquid kinematic viscosity of $\mathrm{ZnO}$ nanolubricant with $135 \mathrm{~nm}$ diameter nanoparticles for various mass fractions at atmospheric pressure. 


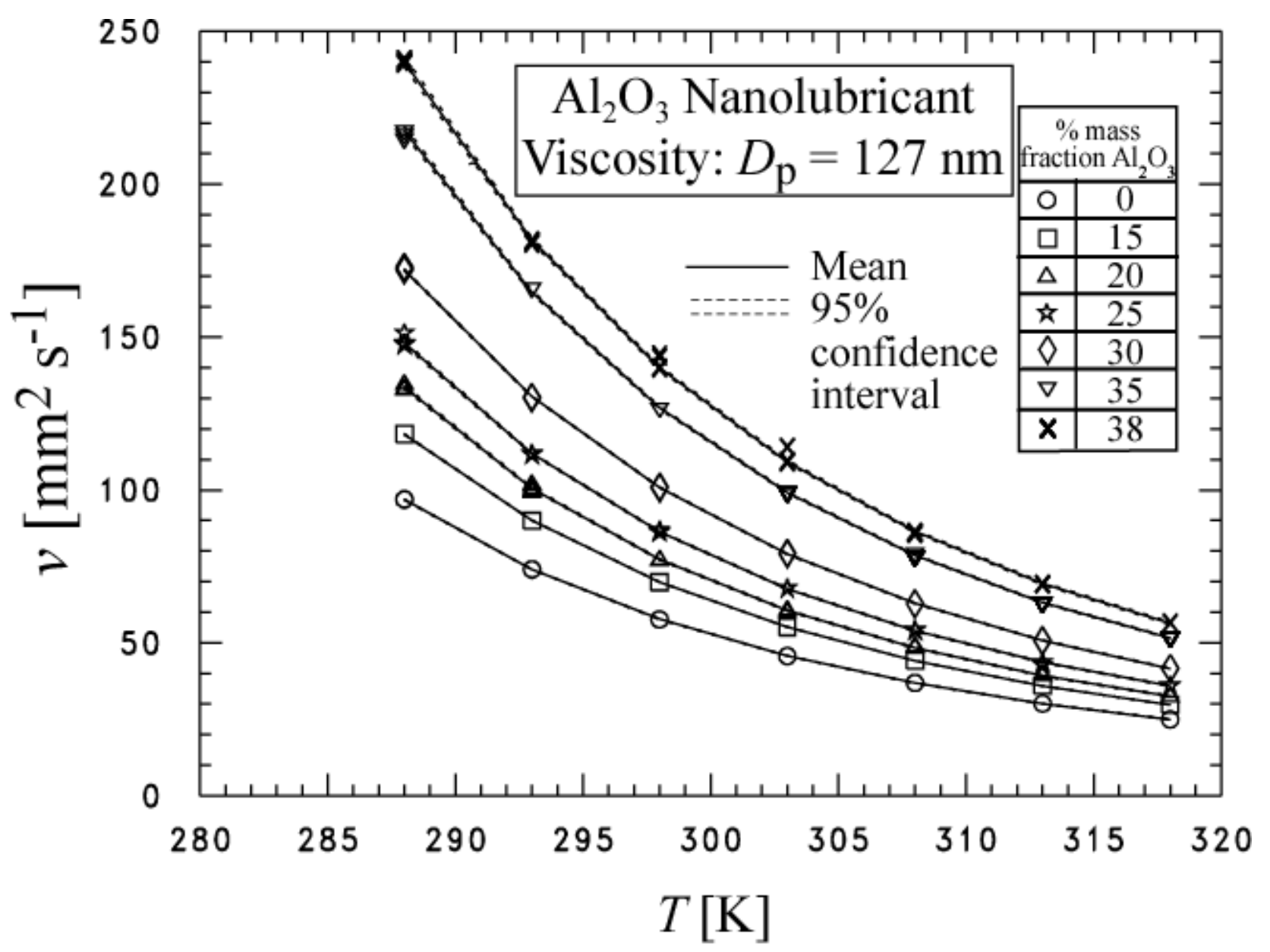

Fig. 6 Measured liquid kinematic viscosity of $\mathrm{Al}_{2} \mathrm{O}_{3}$ nanolubricant with $127 \mathrm{~nm}$ diameter nanoparticles for various mass fractions at atmospheric pressure. 


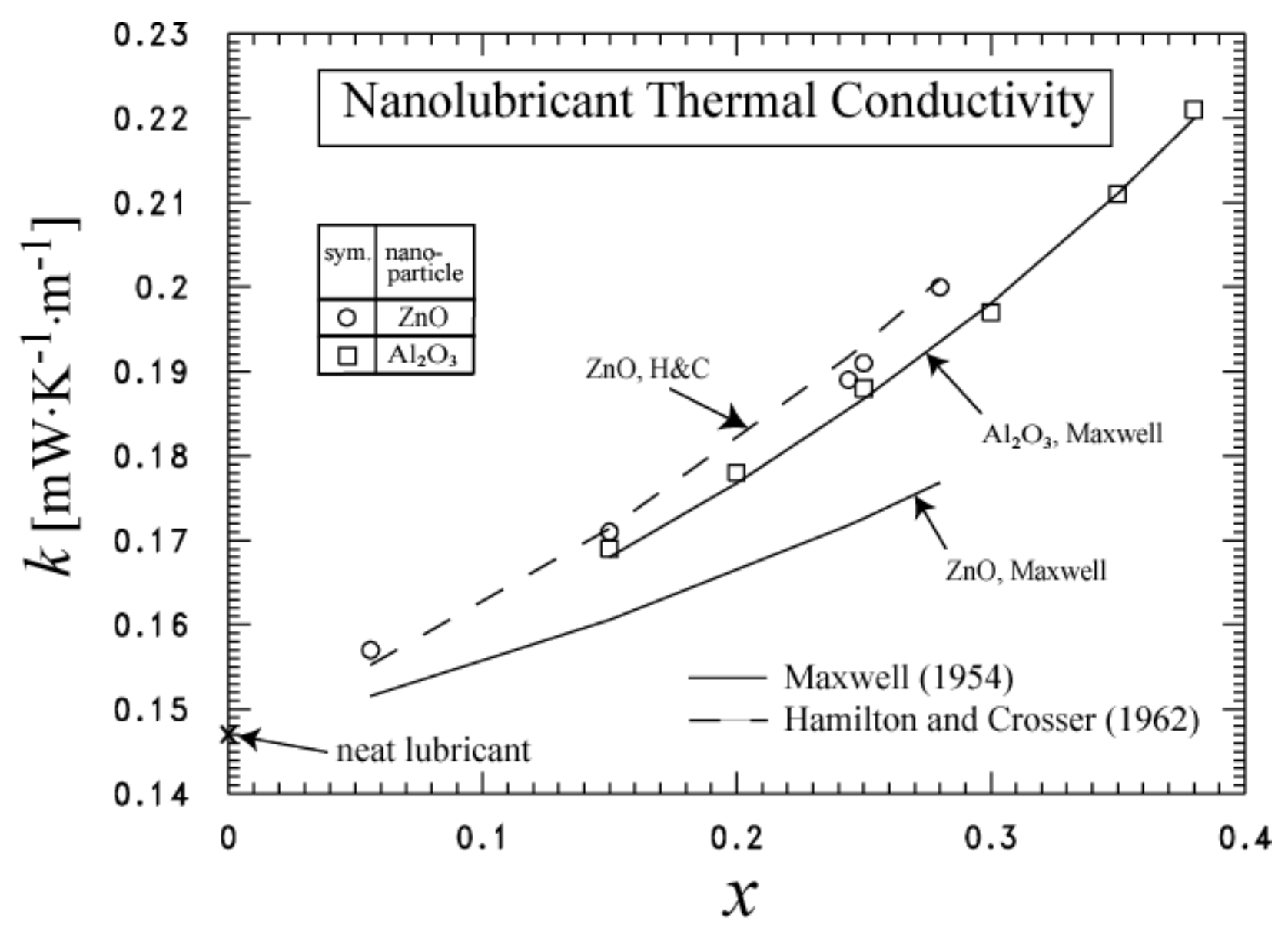

Fig. 7 Comparison of measured thermal conducitivities of nanolubricants to the predictions obtained from Maxwell (1954) and Hamilton and Crosser (1962). 


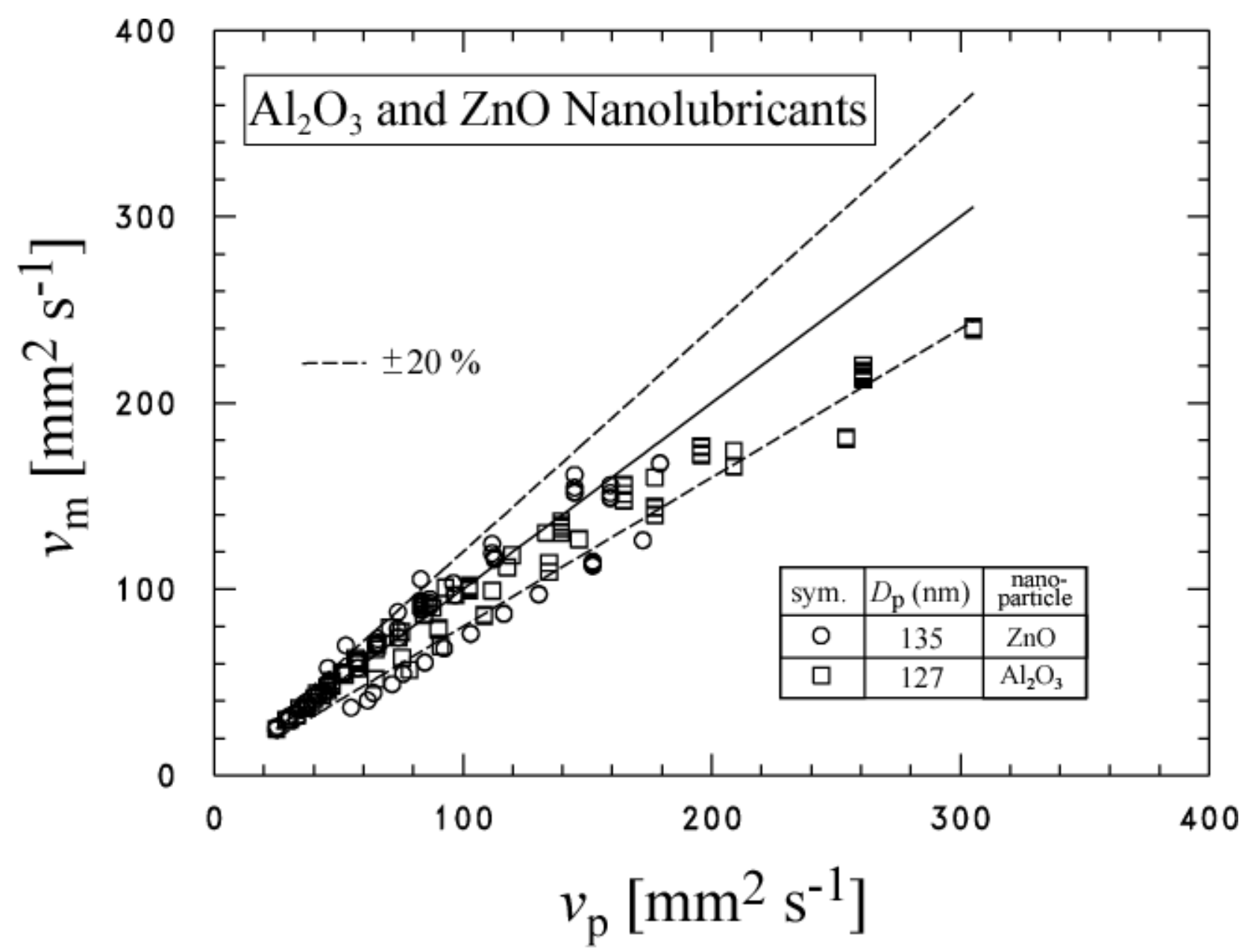

Fig. 8 Comparison of measured viscosity of nanolubricants to the predictions obtained from eq. (5). 


\section{FIGURE CAPTIONS}

Fig. 1 TEMs of $\mathrm{ZnO}$ and $\mathrm{Al}_{2} \mathrm{O}_{3}$ nanolubricants and substrates on which the particles are deposited (Sarkas, 2014, 2015).

Fig. 2 Representative size distributions by number-weighted bases for the $127 \mathrm{~nm}$ and the $135 \mathrm{~nm}$ diameter nanolubricants.

Fig. 3 Measured liquid density of $\mathrm{Al}_{2} \mathrm{O}_{3}$ nanolubricant with $127 \mathrm{~nm}$ diameter nanoparticles for various mass fractions at atmospheric pressure.

Fig. 4 Measured liquid density of $\mathrm{ZnO}$ nanolubricant with $135 \mathrm{~nm}$ diameter nanoparticles for various mass fractions at atmospheric pressure.

Fig. 5 Measured liquid kinematic viscosity of $\mathrm{ZnO}$ nanolubricant with $135 \mathbf{~ n m}$ diameter nanoparticles for various mass fractions at atmospheric pressure.

Fig. 6 Measured liquid kinematic viscosity of $\mathrm{Al}_{2} \mathrm{O}_{3}$ nanolubricant with $127 \mathrm{~nm}$ diameter nanoparticles for various mass fractions at atmospheric pressure.

Fig. 7 Comparison of measured thermal conducitivities of nanolubricants to the predictions obtained from Maxwell (1954) and Hamilton and Crosser (1962).

Fig. 8 Comparison of measured viscosity of nanolubricants to the predictions obtained from eq. (5). 
October 3, 2016

\section{TABLE CAPTIONS}

Table 1. Linear fit of specific volume with respect to temperature:

Table 2. Viscosity fit with respect to temperature: 
October 3, 2016

Table 1. Linear fit of specific volume with respect to temperature: $\rho_{\mathrm{m}}^{-1}\left[\mathrm{~m}^{3} \cdot \mathrm{kg}^{-1}\right]=\mathrm{B}_{0}+\mathrm{B}_{1} T_{\mathrm{r}}[\mathrm{K}]$

\begin{tabular}{|c|c|c|c|c|c|c|c|c|}
\hline \multirow{2}{*}{$x_{\mathrm{np}}$} & \multirow{2}{*}{$\begin{array}{l}\text { Nano } \\
\text { material }\end{array}$} & \multirow{2}{*}{$x_{\mathrm{s}}$} & \multirow{2}{*}{$x_{\mathrm{L}}$} & \multirow{2}{*}{$\begin{array}{c}D_{\mathrm{p}} \\
(\mathrm{nm})\end{array}$} & \multirow{2}{*}{$\begin{array}{l}U_{\rho} \\
(\%)\end{array}$} & \multicolumn{2}{|c|}{ Fitted Constant } & \multirow{2}{*}{$\begin{array}{l}\text { Residual } \\
\text { standard } \\
\text { deviation } \\
\text { of fit }(\%)\end{array}$} \\
\hline & & & & & & $\mathrm{B}_{0}$ & $\mathrm{~B}_{1}$ & \\
\hline 0 & $\mathrm{Al}_{2} \mathrm{O}_{3}$ & 0 & 1.0 & N/A & 0.26 & $0.7972 \times 10^{-5}$ & $0.2003 \times 10^{-5}$ & 0.13 \\
\hline 0.150 & $\mathrm{Al}_{2} \mathrm{O}_{3}$ & 0.032 & 0.818 & 40 & 0.21 & $0.7061 \times 10^{-5}$ & $0.1802 \times 10^{-3}$ & 0.10 \\
\hline 0.200 & $\mathrm{Al}_{2} \mathrm{O}_{3}$ & 0.046 & 0.754 & 40 & 0.20 & $0.6813 \times 10^{-5}$ & $0.1677 \times 10^{-5}$ & 0.09 \\
\hline 0.250 & $\mathrm{Al}_{2} \mathrm{O}_{3}$ & 0.056 & 0.694 & 40 & 0.20 & $0.6552 \times 10^{-5}$ & $0.1583 \times 10^{-3}$ & 0.09 \\
\hline 0.300 & $\mathrm{Al}_{2} \mathrm{O}_{3}$ & 0.063 & 0.637 & 40 & 0.20 & $0.6251 \times 10^{-5}$ & $0.1515 \times 10^{-5}$ & 0.09 \\
\hline 0.350 & $\mathrm{Al}_{2} \mathrm{O}_{3}$ & 0.098 & 0.552 & 40 & 0.20 & $0.6056 \times 10^{-5}$ & $0.1358 \times 10^{-5}$ & 0.09 \\
\hline 0.380 & $\mathrm{Al}_{2} \mathrm{O}_{3}$ & 0.111 & 0.509 & 40 & 0.17 & $0.5879 \times 10^{-5}$ & $0.1312 \times 10^{-5}$ & 0.08 \\
\hline 0.056 & $\mathrm{ZnO}$ & 0.013 & 0.931 & 20 & 0.20 & $0.7477 \times 10^{-5}$ & $0.1993 \times 10^{-5}$ & 0.10 \\
\hline 0.150 & $\mathrm{ZnO}$ & 0.036 & 0.814 & 20 & 0.23 & $0.6892 \times 10^{-5}$ & $0.1782 \times 10^{-5}$ & 0.09 \\
\hline 0.244 & $\mathrm{ZnO}$ & 0.086 & 0.670 & 20 & 0.20 & $0.6308 \times 10^{-3}$ & $0.1564 \times 10^{-3}$ & 0.09 \\
\hline 0.250 & $\mathrm{ZnO}$ & 0.060 & 0.690 & 20 & 0.20 & $0.6281 \times 10^{-5}$ & $0.1553 \times 10^{-5}$ & 0.09 \\
\hline 0.280 & $\mathrm{ZnO}$ & 0.095 & 0.625 & 20 & 0.17 & $0.6086 \times 10^{-5}$ & $0.1492 \times 10^{-5}$ & 0.08 \\
\hline
\end{tabular}


October 3, 2016

Table 2. Viscosity fit with respect to temperature: $\frac{v}{v_{0}}=\exp \left(\mathrm{A}_{0}+\frac{\mathrm{A}_{1}}{T_{\mathrm{r}}}+\mathrm{A}_{2} \ln T_{\mathrm{r}}\right)$

\begin{tabular}{|c|c|c|c|c|c|c|c|c|c|}
\hline \multirow{2}{*}{$x_{\mathrm{np}}$} & \multirow{2}{*}{$\begin{array}{l}\text { Nano } \\
\text { material }\end{array}$} & \multirow{2}{*}{$x_{\mathrm{s}}$} & \multirow{2}{*}{$x_{\mathrm{L}}$} & \multirow{2}{*}{$\begin{array}{c}D_{\mathrm{p}} \\
(\mathrm{nm})\end{array}$} & \multirow{2}{*}{$\begin{array}{l}U_{v} \\
(\%)\end{array}$} & \multicolumn{3}{|c|}{ Fitted Constant } & \multirow{2}{*}{$\begin{array}{l}\text { Residual } \\
\text { standard } \\
\text { deviation } \\
\text { of fit }(\%)\end{array}$} \\
\hline & & & & & & $\mathrm{A}_{0}$ & $\mathrm{~A}_{1}$ & $\mathrm{~A}_{2}$ & \\
\hline 0 & $\mathrm{Al}_{2} \mathrm{O}_{3}$ & 0 & 1.0 & N/A & 0.44 & -45.0487 & 50.5360 & 31.9522 & 0.13 \\
\hline 0.150 & $\mathrm{Al}_{2} \mathrm{O}_{3}$ & 0.032 & 0.818 & 40 & 0.38 & -44.1600 & 49.8576 & 31.0836 & 0.08 \\
\hline 0.200 & $\mathrm{Al}_{2} \mathrm{O}_{3}$ & 0.046 & 0.754 & 40 & 1.08 & -54.2472 & 60.1241 & 40.0155 & 0.51 \\
\hline 0.250 & $\mathrm{Al}_{2} \mathrm{O}_{3}$ & 0.056 & 0.694 & 40 & 0.96 & -45.6323 & 51.5793 & 32.2948 & 0.44 \\
\hline 0.300 & $\mathrm{Al}_{2} \mathrm{O}_{3}$ & 0.063 & 0.637 & 40 & 0.56 & -39.5804 & 45.6583 & 26.9000 & 0.22 \\
\hline 0.350 & $\mathrm{Al}_{2} \mathrm{O}_{3}$ & 0.098 & 0.552 & 40 & 1.66 & -34.4106 & 40.8185 & 22.2432 & 0.81 \\
\hline 0.380 & $\mathrm{Al}_{2} \mathrm{O}_{3}$ & 0.111 & 0.509 & 40 & 1.66 & -34.4106 & 40.8185 & 22.2432 & 0.81 \\
\hline 0.056 & $\mathrm{ZnO}$ & 0.013 & 0.931 & 20 & 0.76 & -43.0884 & 48.6369 & 30.1278 & 0.34 \\
\hline 0.150 & $\mathrm{ZnO}$ & 0.036 & 0.814 & 20 & 0.82 & -44.8062 & 50.5195 & 31.6343 & 0.37 \\
\hline 0.244 & $\mathrm{ZnO}$ & 0.086 & 0.670 & 20 & 0.45 & -48.0232 & 53.9843 & 34.5236 & 0.29 \\
\hline 0.250 & $\mathrm{ZnO}$ & 0.060 & 0.690 & 20 & 2.25 & -36.9557 & 42.9143 & 24.3135 & 1.11 \\
\hline 0.280 & $\mathrm{ZnO}$ & 0.095 & 0.625 & 20 & 0.40 & -46.4837 & 52.5634 & 33.0834 & 0.1 \\
\hline
\end{tabular}

